\title{
2D Simulation of Selected Construction Details of Solid Masonry
}

\author{
Irena Svatošová, and Martina Vodičková
}

\begin{abstract}
When designing a reconstruction of a historical solid masonry, the project architects frequently encounter serious problems, mainly masonry and plaster defects due to humidity. Because to these defects, moulds often grow and irreversibly damage irreplaceable paintings and frescoes on the inner plaster of the historical building. Moreover, the project architects must also deal with the statics of the building and cooperation among construction professionals is needed. This paper is an addition to the field of solid masonry constructions. Based on the simulation of the selected construction details in the two dimensional thermal field in ANSYS software[1] are the examples evaluated on the grounds of the inner surface temperature and a potential water vapour condensation inside the construction.
\end{abstract}

Keywords-Simulation, solid masonry, temperature factor, heat transfer coefficient

\section{INTRODUCTION}

$\mathrm{T}$ HE project architects overseeing a reconstruction of a historical building deal mostly with structural defects, which are fixed by for example using tie rods of prestressed steel supplemented with the thermal insulation and other measures to eliminate the damaging effects of the water vapour condensation in the masonry. The requirements for satisfying the thermo-technical requirements are defined in [3]. Buildings of a common material - solid masonry, come with a specific set of properties, such as high thermal inertia. It is imperative in these buildings to eliminate the temperature and humidity fluctuations. The seasonal use of the objects and their intended purpose - concert halls, galleries, etc. also needs to be taken into account.

The ANSYS FLUENT [1] software and its derivatives are a complex computational environment for the simulation of issues with optimal design of building constructions. The computation is based on the finite element method and the software is optimized for construction physicists, who can simulate both stationary and time-dependent problems. The software solves the problems using partial differential equations. FLUENT defines discrete finite volumes by a non-

Irena Svatošová ${ }^{1}$ is with the Faculty of Civil Engineering, VŠB Technical University of Ostrava, L. Podéště 1875/17, 708 33, Ostrava - Poruba, Czech Republic.

Martina Vodičková ${ }^{2}$ is with the Faculty of Civil Engineering, VŠB Technical University of Ostrava, L. Podéště 1875/17, 708 33, Ostrava - Poruba, Czech Republic. staggered scheme, where all variables are kept in the cell centres of the volumes. ANSYS FLUENT has wide application range, both in $2 \mathrm{D}$ and $3 \mathrm{D}$, ranging from simple temperature calculations, fluid dynamics in closed spaces, composite diffusion, burning, heat exchange to aerodynamics optimization. The software allows a time-dependent solutions, material parameters and boundary conditions input. The results are the desired parameters plotted in the desired region and plane. Another result might be the graphs of the calculations and the parameters itself. This variable use is clearly the strong suit of the software. 2D calculations were chosen for the simulations of construction examples.

\section{THERMO-TECHNICAL REQUIREMENTS FOR BUILDING CONSTRUCTIONS}

Several requirements, specified in [3], must be satisfied. Particularly the requirements for the heat transfer coefficient $U$ (W.m-2K-1) in non-transparent constructions and Uw for hole fillings must be satisfied due to temperature stability in both summer and winter season. There are also strict guidelines for wooden constructions, which are often load-bearing and thus their damage could endanger the whole building.

This article deals with the evaluation of the minimum inner surface temperature of the selected construction details in stationary temperature field. It is also possible to simulate the humidity fields in time and chosen cycles based on the selected boundary conditions. It is theoretically possible to set up the computation to encompass several years with temperature and humidity fluctuation, just as it is possible in long-term 1D simulation in Svoboda Software [2].

\section{TEMPERATURE FACTOR OF THE INNER SURFACE}

Fulfilling the requirements for the temperature factor of the inner surface of building constructions is a prevention for mould growth [3]. This is a relative quantity which is opposed to the inner surface temperature characteristics depend on the design and operating temperatures. Requirements for the temperature factor are set differently for opaque structures and filling of openings (windows, doors). For opaque structure is the formation of mildew exclusion criterion for window criterion of elimination of surface condensation of water vapor. Beyond the exclusion of mold formation is considered a relative humidity of $80 \%$ of the interior surface. If the surface is lower relative humidity, fungus is practically excluded. At high relative humidity, on the contrary the risk is very high. 
The critical surface relative humidity for elimination of surface condensation is $100 \%$ - lower humidity, water vapor condenses on the surface of the structure occurs. The lowest temperature of the inner surface structure factor is determined from the relationship of (1).

$$
f R s i=\frac{\theta s i-\theta e}{\theta a i-\theta e}[-]
$$

$\theta_{\mathrm{ai}}$ wherein the temperature at the inner side of the design evaluation in ${ }^{\circ} \mathrm{C}$ (usually forms of indoor air temperature), $\theta_{\mathrm{e}}$ is the temperature on the outside of the design evaluation in ${ }^{\circ} \mathrm{C}$ (usually design outdoor temperature) and $\theta_{\mathrm{si}}$ is lowest indoor surface temperature in ${ }^{\circ} \mathrm{C}$

Required the lowest indoor surface temperature planar structure with a one-dimensional propagation of heat can be determined from equation (2).

$$
\theta s i=\theta a i-U \cdot R s i \cdot(\theta a i-\theta e)\left[{ }^{\circ} \mathrm{C}\right]
$$

where $U$ is the heat transfer coefficient structure in $\mathrm{W} /\left(\mathrm{m}^{2} \mathrm{~K}\right)$ and $R_{s i}$ is thermal resistance Switch on the inside in $m^{2} K / W$. Resistance to heat transfer $\mathrm{R}_{\mathrm{si}}$ according to [4] and [5] is considering a value of $0.25 \mathrm{~m}^{2} \mathrm{~K} / \mathrm{W}$ for opaque structures and a value of $0.13 \mathrm{~m}^{2} \mathrm{~K} / \mathrm{W}$ for doors and windows.

\section{SELECTED EXAMPLES OF CONSTRUCTION DETAILS OF SOLID MASONRY}

The values in the following Table 1 have been used in the selected examples:

TABLE I

CHARACTERISTICS OF THE MATERIALS USED

\begin{tabular}{|c|c|c|c|}
\hline Material & $\begin{array}{c}\text { Heat transfer } \\
\text { coefficient } \\
{[\mathrm{W} / \mathrm{m} . \mathrm{K}]}\end{array}$ & $\begin{array}{r}\text { Specific } \\
\text { heat capacity } \\
{[\mathrm{J} / \mathrm{kg} . \mathrm{K}]}\end{array}$ & $\begin{array}{c}\text { Volume } \\
\text { density } \\
{[\mathrm{kg} / \mathrm{m} 3]}\end{array}$ \\
\hline CP2 Masonry & 0,86 & 900 & 1800 \\
\hline Concrete & 1,23 & 1020 & 2100 \\
\hline $\begin{array}{c}\text { EPS (Thermal } \\
\text { insulation) }\end{array}$ & 0,034 & 1270 & 30 \\
\hline Soil & 0,7 & 750 & 1600 \\
\hline
\end{tabular}

For better clarity, the details are identified as follows:

Example 4.1 - Horizontal corner without the temperature insulation (TI), variant 1.

Example 4.2 - Horizontal corner with TI, variant 1.

Example 4.3 - Horizontal corner without TI in the floor and with TI on the side of the foundation, variant 2.

Example 4.4 - Horizontal corner with TI in the floor on the foundation side, variant 2

Every detail is shown a diagram giving an overview of the design details and materials used. For each scheme follows the simulation results from ANSYS FLUENT [1] which shows the temperature field detail.

The boundary conditions have been set according to [4], as follows:

Inner air temperature: $+20{ }^{0} \mathrm{C}$

Relative inner air humidity: $50 \%$

Outer air temperature: $-15^{0} \mathrm{C}$

Relative outer air humidity: $84 \%$
Horizontal corner without TI, variant 1

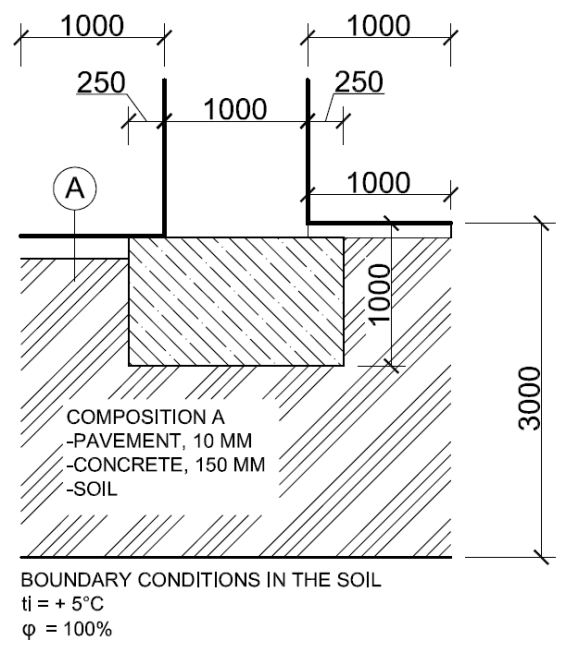

Fig. 1 Example 4.1

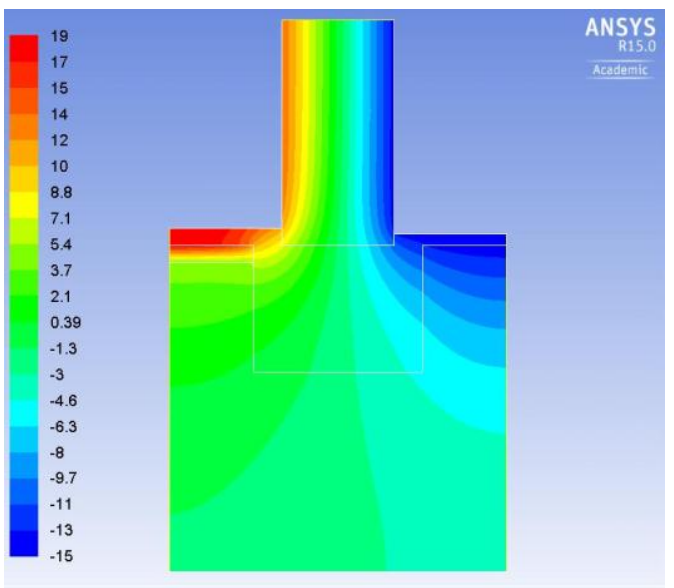

Fig. 2 The results of simulation Example 4.1

\section{Horizontal corner with $\mathrm{TI}$, variant 1}

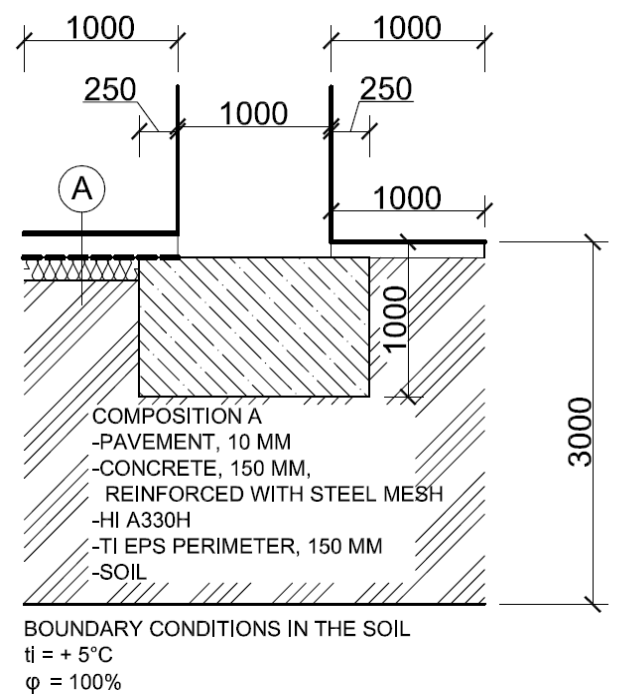

Fig. 3 Example 4.2 


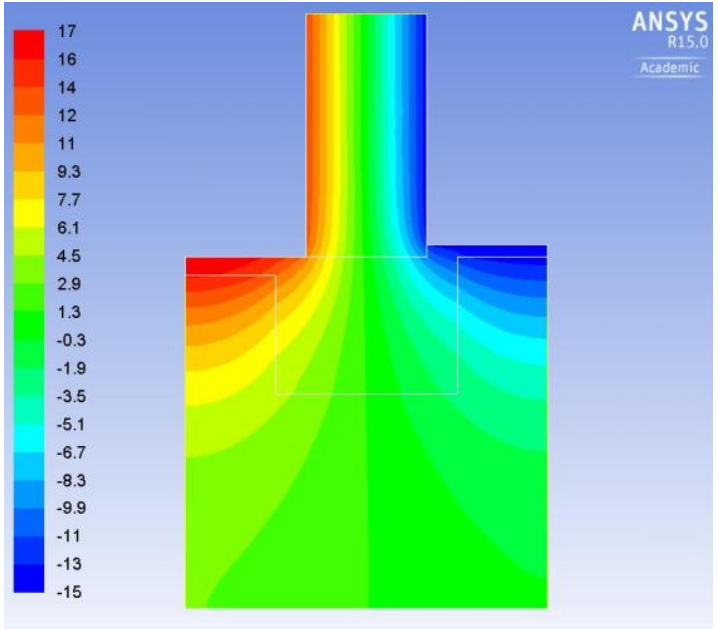

Fig. 4 The results of simulation Example 4.2

\section{Horizontal corner without TI, variant 2}

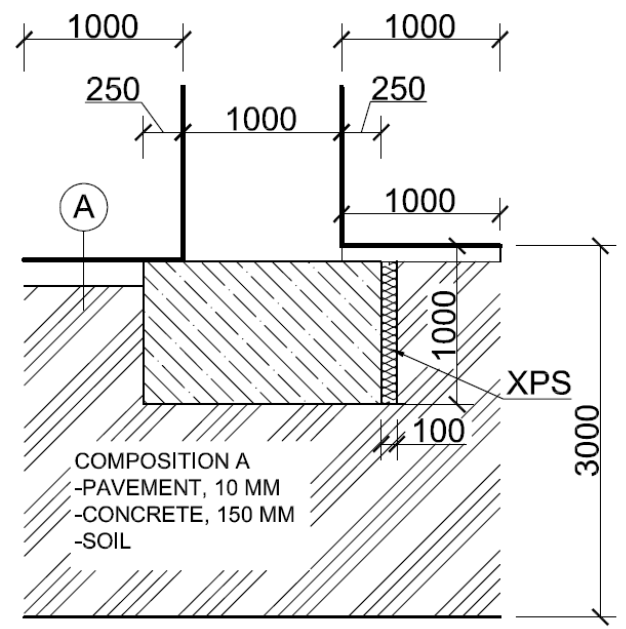

BOUNDARY CONDITIONS IN THE SOIL

$\mathrm{ti}=+5^{\circ} \mathrm{C}$

$\varphi=100 \%$

Fig. 5 Example 4.3

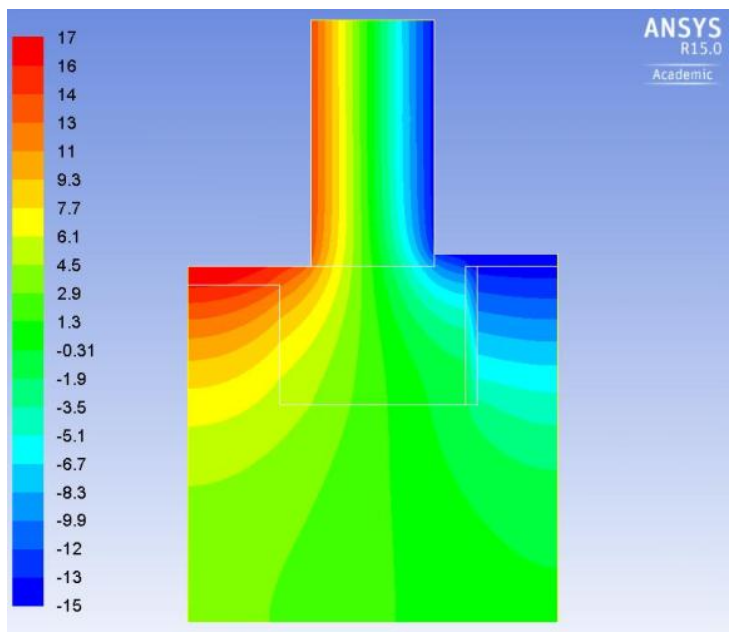

Fig. 6 The results of simulation Example 4.3

\section{Horizontal corner with $\mathrm{TI}$, variant 2}

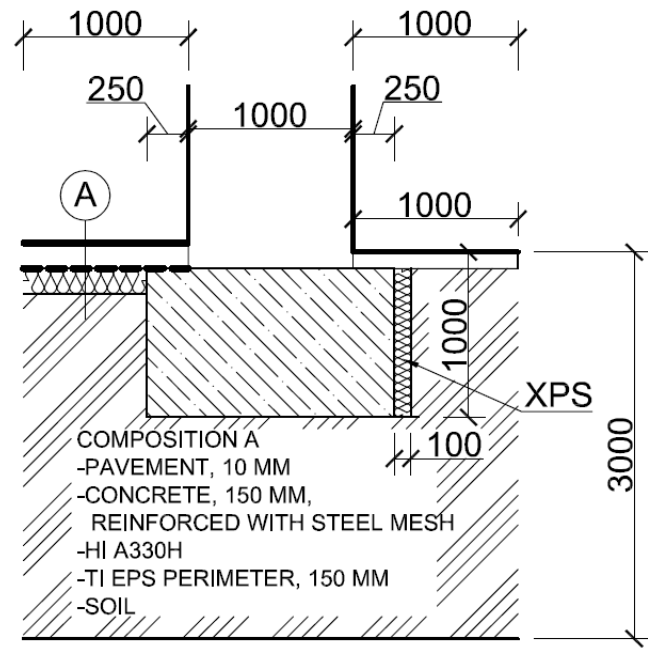

BOUNDARY CONDITIONS IN THE SOIL

$\mathrm{ti}=+5^{\circ} \mathrm{C}$

$\varphi=100 \%$

Fig. 7 Example 4.4

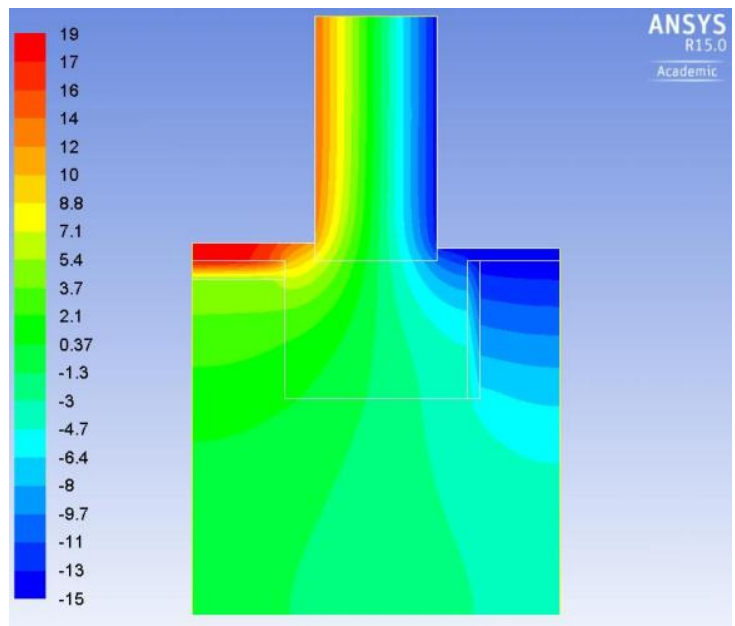

Fig. 8 The results of simulation Example 4.4

\section{EVALUATION}

The result of the simulation is the minimum surface temperature in critical points of the construction details, i.e. corners, where heat escapes in multiple directions. The following Table 2 lists the calculated values.

TABLE II

THE LOWEST TEMPERATURE OF THE SURFACE STRUCTURE

\begin{tabular}{|c|c|c|c|}
\hline Example & $\begin{array}{c}\text { Minimum } \\
\text { surface } \\
\text { temperature } \\
\left({ }^{0} \mathrm{C}\right)\end{array}$ & $\begin{array}{c}\text { Dew } \\
\text { point }\left({ }^{0} \mathrm{C}\right)\end{array}$ & Evaluation \\
\hline 4.1 & 9,17 & 12,62 & unsatisfactory \\
\hline 4.2 & 11,70 & 12,62 & unsatisfactory \\
\hline 4.3 & 11,01 & 12,62 & unsatisfactory \\
\hline 4.4 & 11,92 & 12,62 & unsatisfactory \\
\hline 4.5 & 11,17 & 12,62 & unsatisfactory \\
\hline
\end{tabular}




\section{CONCLUSION}

The resulting temperature shows that sometimes less insulator can be benefit. It must know the consequences insulate that part of the detail. This does not only historical buildings, it is always necessary to consider the detail. The best solution (if thermal techniques already has a similar construction experience) to try several variations of detail and according to the results of the temperature field to decide who will detail for the construction of the given boundary conditions best. Unfortunately, even after the insulation of the floor and foundation design meets the requirements of the temperature of the inner surface factor $f_{R s i}$, is the lowest internal surface temperature. To meet this requirement would certainly help plinth insulation. Since this is a historic building, this step does not need to be in terms of objects of cultural heritage protection is enabled and thermal techniques finds itself in a vicious circle. Solutions to critical details on historic buildings must be a compromise between the requirements and heat technology requirements of conservation.

\section{ACKNOWLEDGMENT}

This work has been supported from conceptual development of science, research and innovations for 2015 awarded to VŠB-TUO from the Czech Ministry of education, youth and sports.

\section{REFERENCES}

[1] Computational software ANSYS, ANSYS, Inc., Pensylvanie, USA.

[2] Doc. Ing. Svoboda,Z. CSc., AREA 2011, Computer software for PC.

[3] ČSN $730540-2$, Thermal protecting of buildings - part 2: Requirements, The Office for Standards, Metrology and Testing, Prague, 2011, including changes Z1: 2012.

[4] ČSN $730540-2$, Thermal protecting of buildings - part 3: Design values of variables, The Office for Standards, Metrology and Testing, Prague, 2011, including changes Z1: 2012.

[5] ČSN EN ISO 13788, Heat and moisture behavior of building components and building elements - Internal surface temperature to avoid critical surface humidity and interstitial condensation Calculation methods, The Office for Standards, Metrology and Testing, Prague, 2013 